\title{
Personalized medicine and stroke prevention: where are we?
}

\author{
This article was published in the following Dove Press journal: \\ Vascular Health and Risk Management \\ 2 December 2015 \\ Number of times this article has been viewed
}

Joosup Kim ${ }^{1,2}$

Amanda G Thrift'

Mark R Nelson ${ }^{3}$

Christopher F Bladin 2,4

Dominique A Cadilhac ${ }^{1,2}$

'Stroke and Ageing Research, Department of Medicine, School of Clinical Sciences at Monash Health, Monash University, Clayton, VIC, Australia; ${ }^{2}$ Public Health, Stroke Division, Florey Institute of Neuroscience and Mental Health, Heidelberg, VIC, Australia; ${ }^{3}$ Discipline of General Practice, School of Medicine, Menzies Institute for Medical Research, University of Tasmania, Hobart, TAS, Australia; ${ }^{4}$ Eastern Health Clinical School, Monash University, Clayton, VIC, Australia
Correspondence: Dominique A Cadilhac School of Clinical Sciences at Monash Health, Monash University, Level I/43-5 I Kanooka Grove, Clayton, VIC 3168, Australia

Tel +6I 395947583

Email dominique.cadilhac@monash.edu
Abstract: There are many recommended pharmacological and non-pharmacological therapies for the prevention of stroke, and an ongoing challenge is to improve their uptake. Personalized medicine is seen as a possible solution to this challenge. Although the use of genetic information to guide health care could be considered as the apex of personalized medicine, genetics is not yet routinely used to guide prevention of stroke. Currently personalized aspects of prevention of stroke include tailoring interventions based on global risk, the utilization of individualized management plans within a model of organized care, and patient education. In this review we discuss the progress made in these aspects of prevention of stroke and present a case study to illustrate the issues faced by health care providers and patients with stroke that could be overcome with a personalized approach to the prevention of stroke.

Keywords: stroke, prevention, personalized health care, education

\section{Introduction}

Stroke is a complex condition usually occurring in people who exhibit vascular risk factors. ${ }^{1}$ Globally, stroke is a leading cause of death and disability. ${ }^{2}$ Approximately, 16.9 million first-ever strokes and 5.9 million stroke-related deaths occur each year. ${ }^{3}$ Several effective lifestyle interventions (eg, smoking cessation) and pharmacological interventions (eg, blood pressure-lowering medication) are recommended for the prevention of stroke. ${ }^{4,5}$ However, suboptimal uptake of these interventions means there remain opportunities to improve the prevention of stroke to reduce this burden. ${ }^{6}$ Personalized medicine is a growing field in which a range of diagnostic tests, such as genetic screening and other risk stratification tools, will enable clinicians to develop evidence-based and individually tailored care plans. Additionally, personalized medicine requires consideration of patient preferences and their circumstances in clinical decision making. The objective of this review is to provide an overview of prevention of stroke and discuss how a personalized approach can improve the likely success of preventing stroke. To provide context for the issues faced in clinical practice, we first provide a case study that illustrates the difficulties encountered in the prevention of stroke.

\section{Case study: an individualized management program for secondary stroke prevention}

We conducted a qualitative analysis of the topics discussed between nurses and patients with stroke or transient ischemic attack (TIA) at education visits that were conducted 
as part of the intervention tested in the STAND FIRM (Shared Team Approach between Nurses and Doctors For Improved Risk factor Management) randomized controlled trial. ${ }^{7}$ The aim of the STAND FIRM trial was to improve the management of risk factors in people who returned home after being hospitalized for stroke or TIA. Briefly, the intervention included the use of a management plan that was prepared following a comprehensive risk factor assessment.

Nurses conducted education visits after the baseline assessment, and after 3-month and 12-month outcome assessments using a standard education syllabus on the prevention of stroke. The education provided was tailored to each patient and so parts of the syllabus were discussed only when relevant to the patient. Standardized literature on a range of topics was provided to patients at their request. However, the nurses often discussed topics outside the scope of the regular syllabus. The nurses also encouraged patients to discuss their main concerns of having had a stroke or TIA, and documented these concerns. The nurses also documented the advice they provided to patients to help resolve their main concerns, as well as information provided on stroke prevention using a pro forma specifically developed for these visits. An inductive approach was used to identify and summarize the major themes and subthemes derived from content analysis of these data. ${ }^{8}$

\section{Information requirements: knowledge gaps and misconceptions}

Patients reported a variety of issues with the information provided to them regarding their stroke. Some patients reported to the nurses that they did not know the reason they suffered a stroke. This appeared to be a source of anxiety for these patients. Many patients also reported not understanding the reasons why their medications had been prescribed to them. In these instances, the nurses explained the causes of stroke, explained the reasons for taking the medications, and/or encouraged patients to take further interest in their medications.

Some patients were only partially aware of the reasons for being prescribed their medications and had misconceptions about the need for secondary prevention medications when risk factors were within a normally acceptable range. Other patients, who had suffered an ischemic stroke, were unhappy to be taking a cholesterol lowering medication while others questioned the need for these medications since they believed their cholesterol levels were satisfactory. For some patients, this desire to cease medication was influenced by the side effects experienced from taking the medication. For example, at the education visit that occurred 12 months after recruitment, a patient was unhappy about being prescribed a cholesterol lowering medication because he was content with his current cholesterol level and had concerns that the medication would be detrimental to his liver. Nurses clarified the rationale for taking medications and reinforced that these medications were prescribed according to guidelines and to prevent recurrent stroke.

\section{Issues with utilization of medications}

The nurses noted that some patients had poor adherence to their medications. There were also instances where the patients themselves had decided to cease medications or had declined secondary prevention medications. Sometimes patients stated that they simply forgot to take medications. The nurses discussed ways for these patients to remember taking their medications such as developing a routine for taking medications or using a dosing aid. The nurses also encountered patients who had not taken medications because they had run out and then not renewed the script. These examples all highlighted the importance of reinforcing the reasons for taking their medications.

Financial issues were discussed in regard to medications. Some patients reported that the medications they were taking were expensive. One patient (61 years old, ischemic stroke) informed the nurse of the need to "budget for medications" for this reason. Another patient (72 years old, ischemic stroke) expressed concern that she would not be able to afford the medications when she stopped working. Regular review of medications would be ideal in order to ensure the ongoing suitability of medications from a medical and financial perspective. Regular review and reminders to renew scripts may assist as part of a personalized approach to stroke prevention.

As expected, side effects were a major reason for poor adherence or self-discontinuation of a medication. One patient (34 years old, ischemic stroke) "declined cholesterol and blood pressure medications" and was intending to "try natural therapies and relaxation" because of a desire "to avoid side effects of medications". One patient (30 years old, ischemic stroke) admitted to taking aspirin "intermittently" as she suspected that it was causing stomach irritation. At a later education visit, this patient was still not taking aspirin regularly as she believed it was not "vital" to take this every day. This patient was informed about the importance of aspirin for secondary prevention. Another patient ( 82 years old, female, ischemic stroke) had been recently re-prescribed an antihypertensive medication, but had not recommenced 
taking it because she did not want the return of side effects that she had previously suffered when taking this medication. Another patient (69 years old, male, ischemic stroke) had been advised to take a cholesterol lowering medication by his general practitioner (GP), but had ceased taking this medication after reading about its possible side effects. When patients reported that side effects were reasons for poor adherence, the nurses encouraged them to seek alternative medications. For example, the patient who believed aspirin to be causing gastric irritation was encouraged to discuss using enteric-coated aspirin with their GP. Some patients experienced symptoms from taking secondary prevention medications, but tolerated the symptoms and reported that they were adherent to the medications. For these patients, the nurses suggested that they speak with their GPs to receive more frequent monitoring or to find alternative secondary prevention medications.

Some patients reported that they had completely ceased taking medications due to side effects. For example, a patient (84 years old, female, ischemic stroke) had ceased taking an antihypertensive medication after developing a cough, and was concerned that this would result in increased blood pressure. The nurse advised this patient to regularly monitor her blood pressure and to discuss alternative medications with her GP.

\section{Lessons}

Our case study illustrates the many challenges faced by health care providers and patients in the prevention of stroke (Table 1). The main issues identified were: 1) knowledge gaps and misconceptions; 2) factors influencing medication adherence such as communication between health care providers and patients; and 3) the need for both reinforcement of information and review of costs of medications. Intricacies of patients necessitate a personalized approach to the prevention of stroke that incorporates targeted education, regular review and consideration of personal circumstances, including affordability of care where alternate solutions may be needed.

Table I Issues with the prevention of stroke and their potential solutions

\begin{tabular}{ll}
\hline Issues & Potential solutions \\
\hline $\begin{array}{l}\text { Knowledge gaps and misconceptions } \\
\text { Poor adherence }\end{array}$ & Educational interventions \\
- Forgetfulness & Educational interventions \\
- Cost of therapy & Regular review \\
- Side effects & \\
Communication with health care & Individualized management \\
providers and continuity of care & programs with regular review \\
\hline
\end{tabular}

\section{Prevention of stroke}

In the context of stroke, primary prevention refers to use of prevention strategies or therapies for people who have not yet suffered a stroke or TIA, ${ }^{4}$ while secondary prevention refers to similar approaches that are aimed at people who have already suffered a stroke or TIA to prevent stroke recurrence. ${ }^{5}$ Although the interventions used for primary prevention of stroke are similar to those for secondary prevention, there are important differences in their approach. In addition, since stroke and heart disease have similar risk factors, primary prevention strategies are often based on reducing the risk of cardiovascular disease collectively because the recommendations for treatment are often the same.

In the past, the focus of primary prevention was on the treatment of individual risk factors, with treatment initiated when a threshold for that risk factor was exceeded. However, individual risk factors are not a good measure of cardiovascular risk since most risk factors have a continuous and linear association with risk of disease events occurring, and most people have more than one risk factor. Assessment of cardiovascular risk on the basis of the combined effect of multiple risk factors (often referred to as "absolute" or "global" cardiovascular risk) is more appropriate because the cumulative effects of multiple risk factors may be additive or synergistic. Therefore, the focus of primary prevention has been shifting from the treatment of individual risk factors to the management of absolute risk. Similar to other countries, in Australia, the National Vascular Disease Prevention Alliance has endorsed algorithms and tables for risk assessment and provides a summary of the recommended assessment pathway, interventions, treatment targets, and follow-up. ${ }^{9}$

Approaches to controlling risk factors for cardiovascular disease differ according to the degree of absolute risk. Lifestyle modifications are recommended for those at lower risk while more intensive treatment involving medications is recommended for those at greater risk. Importantly, a risk factor is treated, even when within a normally acceptable range, if absolute risk is high (eg, $>15 \%$ chance of a stroke or heart attack within 5 years). Over time, these risk calculation tools, that combine the effects of modifiable (eg, smoking and diabetes) and non-modifiable (eg, age and sex) risk factors, have become more sophisticated. For example, the recently released "Stroke Riskometer" is available as a smart phone application and includes a risk calculation based on a broader range of risk factors than previous tools based on the Framingham equations. ${ }^{10,11}$ This may improve precision of risk, but ongoing validation work is needed. 
Although positive lifestyle modifications for smoking, diet, and exercise are universally recommended, the major difference between primary and secondary stroke prevention is in regard to the provision of medications. Secondary prevention of stroke involves providing pharmacological and nonpharmacological interventions irrespective of absolute risk since patients with stroke are by definition already at "high risk". 5 The risk of stroke recurrence is approximately $11 \%$ at 1 year, $26 \%$ at 5 years, and $40 \%$ at 10 years post-stroke. ${ }^{12}$ There is also a high risk of stroke in the short-term after TIA: $9.9 \%$ at 2 days, $13.4 \%$ at 30 days, and $17.3 \%$ at 90 days. ${ }^{13}$ Since these risks are much greater than in the normal population, more aggressive pharmacological interventions are warranted. Importantly, secondary prevention strategies are more cost-effective than primary prevention strategies largely because of this very high risk, with the acknowledgment that they apply to fewer people. ${ }^{14}$

Medications recommended in guidelines for the prevention of recurrent stroke differ according to the type of stroke that the patient has suffered and the presence of other risk factors. ${ }^{5}$ These recommendations, supported by meta analyses (Table 2), are summarized below:

- blood pressure-lowering therapy for patients who have suffered a stroke or TIA. ${ }^{15}$

- Cholesterol lowering therapy for patients who have suffered an ischemic stroke or TIA. ${ }^{16}$

- Antiplatelet therapy for patients without atrial fibrillation who have suffered an ischemic stroke or TIA. ${ }^{17,18}$

- Anticoagulant therapy for patients with atrial fibrillation who have suffered an ischemic stroke or TIA. ${ }^{19}$

- New oral anticoagulants (NOACs) may be used as an alternative to warfarin. Compared to warfarin all NOACs had a reduced risk of hemorrhagic stroke, and were either superior or non-inferior in terms of major bleeding risk, except for gastrointestinal bleeding. ${ }^{20}$ There are also practical advantages for the use of NOACs over warfarin: ${ }^{21}$ they are simpler to monitor because they have fixed doses and do not require monitoring of anticoagulant effects; have a short half-life; and have few drug and food interactions. The major disadvantages of NOACs include a short half-life which makes NOACs ineffective for patients with poor compliance, the absence of a blood test to determine the strength of the anticoagulant effect, no antidote for reversal of the anticoagulant effect, concerns about safety of thrombolysis while on NOACs, and the need to monitor renal function because of increases in plasma concentrations of NOACs in people with poor renal function. ${ }^{21}$ NOACs are also more expensive than warfarin, but have been shown to be cost-effective for the secondary prevention of stroke. ${ }^{22}$ In Australia, these medications have been subsidized by the government under the Pharmaceutical Benefits Scheme (www.pbs.gov.au/).

The cumulative risk reductions from using a combination of these medications for secondary prevention may be substantial. Although there is limited direct evidence of the combined benefit of these medications for patients who have suffered a stroke or TIA, in simulation modeling of patients with heart attack, an estimated $75 \%$ relative risk reduction in stroke, heart attack, and death could be achieved with lifestyle modification and a combination of secondary prevention medications. ${ }^{23}$ Similar benefits could be elicited for patients with stroke since stroke and heart attack have a similar pathophysiology and recommended treatment. The use of combination therapy may also be favorable because it produces greater and timelier effects at lower doses of medications, minimizes side effects, and improves adherence by simplifying the medication regimen. ${ }^{24-26}$

Table 2 Summary of meta analyses of antihypertensive, antiplatelet, anticoagulant, and cholesterol lowering drugs used for secondary prevention in patients with stroke and TIA

\begin{tabular}{|c|c|c|c|c|c|}
\hline Study, year & Type of patients & $\begin{array}{l}\text { Primary } \\
\text { outcome }\end{array}$ & Treatment & Control & $\begin{array}{l}\text { RRR with } \\
\text { treatment \% (Cl) }\end{array}$ \\
\hline Lakhan and Sapko, 200915 & Stroke, TIA & Stroke, MI, VD & Blood pressure-lowering & Placebo & $31(14-43)$ \\
\hline Manktelow and Potter, $2009^{16}$ & Stroke, TIA & Stroke & Statin & Placebo & $12(0-23)$ \\
\hline Algra and van Gijn, $1999^{17}$ & Non-disabling stroke, TIA & Stroke, MI, VD & Aspirin & Placebo & $13(6-19)$ \\
\hline Halkes et al, $2008^{18}$ & Ischemic stroke, TIA & Stroke, MI, VD & Aspirin + MR-DP & Aspirin & $18(8-28)$ \\
\hline Saxena and Koudstaal, $2004^{19}$ & $\begin{array}{l}\text { NRAF and minor ischemic } \\
\text { stroke or TIA }\end{array}$ & Stroke, MI, VD & Warfarin & Aspirin & $33(9-50)$ \\
\hline \multirow[t]{2}{*}{ Ntaios et al, $2012^{20}$} & NRAF and stroke or TIA & $\begin{array}{l}\text { Stroke, systemic } \\
\text { embolism }\end{array}$ & NOACs & Warfarin & $15(I-26)$ \\
\hline & & Major bleeding & NOACs & Warfarin & $14(I-25)$ \\
\hline
\end{tabular}

Abbreviations: TIA, transient ischemic attack; MI, myocardial infarction; VD, vascular death; NRAF, non-rheumatic atrial fibrillation; MR-DP, modified-release dipyridamole; RRR, relative risk reduction; $\mathrm{Cl}$, confidence interval; NOACs, new oral anticoagulants. 


\section{Poor adherence and treatment gaps}

Adherence to a medication regimen is generally defined as the extent to which patients take medications as prescribed by their health care providers. ${ }^{27}$ The level of adherence that is deemed as acceptable varies from study to study, but better adherence to therapy is associated with better outcomes. ${ }^{28,29}$ In an Italian study, $51 \%$ of patients newly treated for hypertension were adherent to their medication..$^{30}$ There is also some evidence that even patients with stroke have poor adherence to medications used for stroke prevention. In a study conducted in Canada, Khan et al assessed adherence to antihypertensive medications at 1 year after stroke. ${ }^{31}$ Depending on the type of antihypertensive medication prescribed, $62 \%-76 \%$ of patients were taking their medication on $\geq 80 \%$ of days. ${ }^{31}$

There is evidence that the utilization of therapies for the prevention of stroke can be improved. In a study conducted in the Netherlands, de Koning et al ${ }^{32}$ investigated the quality of care in general practice provided to patients prior to their hospitalization for stroke. The management of hypertension, diabetes mellitus, TIA, peripheral vascular disease, cardiac failure, and angina pectoris prior to stroke was assessed by a panel of GPs. These GPs adjudicated that one-third of the patients received suboptimal care that possibly or likely failed to prevent stroke. There is also evidence that patients who have had a stroke are receiving suboptimal care. ${ }^{6}$

\section{Definition of personalized medicine}

Personalized medicine may solve the problems of managing risk factors and preventing stroke. There is no universally accepted definition of personalized medicine. ${ }^{33}$ Some definitions incorporate the use of genetic information to individualize the provision of health care. ${ }^{33,34} \mathrm{~A}$ definition recommended by Schleidgen et $\mathrm{al}^{33}$ following a systematic review, is that:

personalized medicine seeks to improve stratification and timing of health care by utilizing biological information and biomarkers on the level of molecular disease pathways, genetics, proteomics as well as metabolomics.

Similar terms to personalized medicine include "precision medicine" 35 and to a lesser extent "patient-centered care". ${ }^{36}$ To date, routine genetic testing has not been adopted into strategies for preventing stroke because the genes associated with stroke that have been identified do not adequately predict overall stroke risk. ${ }^{34}$ However, genetic information has applications in determining the effectiveness of medications for an individual. ${ }^{37}$ For example, genetic testing can be used to improve the delivery of anticoagulant therapy. 38,39
The major limitation of the definition proposed by Schleidgen et $\mathrm{al}^{33}$ is that it does not incorporate individualized aspects of a patient-centered approach to health care. Patient-centered health care emphasizes consideration of patients' preferences and values, provision of emotional and physical support, education, coordination of care, and involvement of family and friends. ${ }^{36}$ This can be facilitated with discussion between health care providers and patients, and shared decision-making. ${ }^{40}$ The tools used to assist clinical decision-making usually incorporate routinely collected individual clinical information that assist clinicians to deliver appropriate health care for a particular patient. Clearly, health care can be individualized regardless of whether or not genetic information is available to assist clinical decision-making. Therefore, we have adopted a broader view of personalized medicine that combines the definition proposed by Schleidgen et $\mathrm{al}^{33}$ and aspects of patient-centered health care.

\section{Tools to support clinical decision-making}

To facilitate personalized medicine, time-poor clinicians require effective tools to support their clinical decisionmaking. In future, there is likely to be a greater reliance on software to assist clinical decision-making as this is expected to improve the quality of care provided.$^{41}$ Individual clinical information can be used within the software to support a decision to treat. Evidence for the use of clinical decisionsupport software for the prevention of stroke is limited, but some benefit for its use for the management of risk factors for stroke has been demonstrated. ${ }^{42}$

There are increasingly effective risk stratification tools that assist with clinical decision-making, particularly in the primary prevention setting. In general, risk stratification tools have become more personalized with their increasing complexity. There is some qualitative evidence that the absolute cardiovascular risk approach to conveying risk is considered by patients to be personalized, ${ }^{43}$ but this method of conveying risk is underutilized by clinicians. ${ }^{44}$ The development of the Stroke Riskometer and other similar smart phone applications may facilitate better utilization of an absolute risk approach to prevention management in future. ${ }^{11}$

Risk stratification is particularly important in the decision to prescribe an anticoagulant medication to patients with atrial fibrillation. Although there is evidence from randomized controlled trials of an overall benefit for patients with atrial fibrillation prescribed anticoagulant medications, patients taking these medications are at an increased risk of intracerebral hemorrhage. In addition, stroke in patients with atrial fibrillation is not always embolic. Therefore, the risks 
and benefits of anticoagulant therapy need to be carefully considered. Use of the $\mathrm{CHA}_{2} \mathrm{DS}_{2}-\mathrm{VASc}^{45}$ and HAS-BLED ${ }^{45}$ risk stratification tools are recommended to help weigh up the risks of ischemic stroke and intracerebral hemorrhage in patients with atrial fibrillation and therefore assist with the decision to prescribe anticoagulant medications. The type of anticoagulant medication (eg, warfarin or NOACs) prescribed should take into account the personal circumstances of the patient and determine the best fit for ensuring adherence and maintaining quality of life, since there are advantages and disadvantages of each medication.

\section{Individualized management programs}

As described earlier, in the long term after stroke many patients are not prescribed medications that may help to prevent recurrent stroke ${ }^{46}$ and often they have poorly controlled risk factors ${ }^{6,47}$ and unmet needs. ${ }^{48}$ An individualized care plan, which is developed with the patient while in hospital, may improve continuity of care once the patient returns to the community. In Australia, it is recommended that patients discuss their individualized care plan with their GP once they are discharged from hospital. ${ }^{49}$ GPs and patients are encouraged to review these plans periodically. The plan typically includes information on risk factors, therapy and equipment required, and contact details of community support services. In Australia, there is an existing framework for the use of these plans that is Medicare-funded in order to provide additional incentive for GPs to use them. ${ }^{50}$
Individualized secondary prevention programs for patients with heart disease have been shown to reduce mortality by up to $25 \%$, reduce recurrent cardiovascular events by up to $24 \%$, improve prescription of medications, improve quality of life, and improve the management of several risk factors. ${ }^{51,52}$ Several of these studies have involved individualized risk factor assessment and management provided through general practices (Table 3). ${ }^{52}$ Trials of programs for the secondary prevention of stroke are gaining momentum. ${ }^{53}$ So far, programs for the secondary prevention of stroke have been tested in only a few clinical trials that have involved relatively small numbers of patients with stroke. ${ }^{53}$ These studies have been heterogeneous and have primarily demonstrated benefits for lowering blood pressure and promoting lifestyle change, but not for reducing the risk of cardiovascular disease (Table 4). However, economic modeling provides evidence for cost-effectiveness of individualized care for the management of blood pressure and lifestyle risk factors in patients who have suffered a stroke, with a median cost per quality adjusted life year gained estimated at less than AU\$5,000 (reference year 2004). ${ }^{14}$

Nurse-led care offers a complementary alternative to prevention management directed by GPs. This form of care has been shown to be effective for reducing blood pressure in patients with hypertension; ${ }^{54}$ improving glycemic control and reducing mortality in patients with diabetes, ${ }^{55}$ and for reaching target cholesterol levels. ${ }^{56}$ Nurse-led care can also have effects on preventing cardiovascular events in people at risk of stroke. In a study by Hendriks et al, ${ }^{57} 712$ patients

Table 3 Randomized controlled trials of programs for risk management of patients with coronary heart disease involving general practitioners

\begin{tabular}{|c|c|c|c|c|}
\hline Study, year & $\mathbf{n}$ & Follow-up & Primary outcome measure & Significant primary outcome results \\
\hline $\begin{array}{l}\text { Murchie et al, } \\
2003^{58}\end{array}$ & 1,343 & 5 years & $\begin{array}{l}\text { - Improvements in prescription of secondary } \\
\text { prevention therapies } \\
\text { - Total mortality } \\
\text { - Coronary events }\end{array}$ & $\begin{array}{l}\text { - Improved pharmacological and lifestyle } \\
\text { management } \\
\text { - Decreased risk of mortality } \\
\text { - Decreased risk of coronary events }\end{array}$ \\
\hline $\begin{array}{l}\text { Munoz et al, } \\
2007^{59}\end{array}$ & 983 & 3 years & $\begin{array}{l}\text { - Readmission for unstable angina, AMI, heart } \\
\text { failure, arrhythmias, stroke, or coronary artery } \\
\text { revascularization }\end{array}$ & $-\mathrm{Nil}$ \\
\hline $\begin{array}{l}\text { Khunti et al, } \\
2007^{60, *}\end{array}$ & 1,316 & I year & $\begin{array}{l}\text { - Prescription of } \beta \text {-blocker for patients with AMI } \\
\text { - Total cholesterol }<5 \mathrm{mmol} / \mathrm{L} \text { for patients with CHD } \\
\text { - Prescription of ACEl for patients with LVSD }\end{array}$ & $\begin{array}{l}\text { - More patients with AMI prescribed } \beta \text {-blocker } \\
\text { - More patients with } \mathrm{CHD} \text { cholesterol }<5 \mathrm{mmol} / \mathrm{L}\end{array}$ \\
\hline $\begin{array}{l}\text { Wood et al, } \\
2008^{61}\end{array}$ & 1,940 & I year & $\begin{array}{l}\text { - Blood pressure } \\
\text { - Blood lipids and glucose } \\
\text { - Prescription of secondary prevention medications }\end{array}$ & $\begin{array}{l}\text { - Reduced blood pressure } \\
\text { - Reduced low-density lipoprotein levels } \\
\text { - Increased prescriptions to statins }\end{array}$ \\
\hline $\begin{array}{l}\text { Murphy et al, } \\
2009^{62}\end{array}$ & 903 & 18 months & $\begin{array}{l}\text { - Target levels for blood pressure and cholesterol } \\
\text { - Hospital admission } \\
\text { - Changes in physical and mental health status }\end{array}$ & - Decreased hospitalization \\
\hline
\end{tabular}

Note: *Patients with coronary heart disease and chronic heart failure.

Abbreviations: AMI, acute myocardial infarction; CHD, coronary heart disease; LVSD, left ventricular systolic dysfunction; ACEI, ACE inhibitor. 
Table 4 Randomized controlled trials of programs for risk management of patients with stroke involving general practitioners

\begin{tabular}{|c|c|c|c|c|}
\hline Study, year & $\mathbf{n}$ & Follow-up & Primary outcome measure & $\begin{array}{l}\text { Significant primary outcome } \\
\text { results }\end{array}$ \\
\hline $\begin{array}{l}\text { Ellis et al, } \\
2005^{63}\end{array}$ & 205 & 5 months & $\begin{array}{l}\text { - Risk factors: SBP; DBP; total cholesterol; } \mathrm{HbA}_{\mathrm{Ic}} \\
\text { - Combined risk factor control }\end{array}$ & $-\mathrm{Nil}$ \\
\hline $\begin{array}{l}\text { Joubert et al, } \\
2009^{64}\end{array}$ & 186 & I year & - Blood pressure level & - Reduction in SBP \\
\hline $\begin{array}{l}\text { Allen et al, } \\
2009^{65}\end{array}$ & 380 & 6 months & $\begin{array}{l}\text { - Risk factor control: SBP }>140 \mathrm{mmHg} \text {; DBP }>90 \mathrm{mmHg} \text {; total } \\
\text { cholesterol }>180 \mathrm{mg} / \mathrm{dL} ; \mathrm{HbA}_{\mathrm{lc}}>6.5 \% \\
\text { - Proportion of participants on anticoagulants } \\
\text { - Proportion of participants using method for medication compliance }\end{array}$ & $\begin{array}{l}\text { - Improved knowledge of stroke and } \\
\text { behaviors for stroke risk reduction }\end{array}$ \\
\hline $\begin{array}{l}\text { Wolfe et al, } \\
2010^{66}\end{array}$ & 523 & I year & $\begin{array}{l}\text { - Prescription of antihypertensive medication } \\
\text { - Antiplatelet drug prescription } \\
\text { - Smoking cessation }\end{array}$ & $-\mathrm{Nil}$ \\
\hline $\begin{array}{l}\text { Flemming et al, } \\
2013^{67}\end{array}$ & 41 & I year & $\begin{array}{l}\text { - Change in cardiovascular risk factors (SBP; LDL; HDL; triglycerides; } \\
\text { HbA }{ }_{1 \mathrm{lc}} \text {; BMI; Framingham cardiovascular risk score) } \\
\text { - Achievement of targets for cardiovascular risk factors } \\
\text { - Number of vascular events } \\
\text { - Adherence to secondary prevention medication }\end{array}$ & $\begin{array}{l}\text { - Reduction in LDL, Framingham } \\
\text { cardiovascular risk score, and SBP }\end{array}$ \\
\hline
\end{tabular}

Abbreviations: SBP, systolic blood pressure; DBP, diastolic blood pressure; $\mathrm{HbA}_{1 \mathrm{c}}$, glycated hemoglobin; LDL, low-density lipoprotein; HDL, high-density lipoprotein; BMI, body mass index.

with $\mathrm{AF}$ were randomized to nurse-led or usual care. Nurses used guideline-based decision-support software to recommend therapy. Symptoms, type of AF, and the risk of stroke were considered when making the recommendations. These recommendations were approved by a cardiologist. Patients in the nurse-led care group had a $72 \%$ reduction in the risk of cardiovascular death and a $34 \%$ reduction in the risk of cardiovascular hospitalizations when compared to patients provided with usual care.

\section{Education to improve adherence to therapies}

Many factors have been found to affect adherence to therapy, including health system, patient, and clinician factors. ${ }^{27}$ For example, non-adherence due to cost of medications may be affected by all three factors: high medication costs which may discourage utilization; patients may not purchase recommended medications because the cost of the medication outweighs their perceived benefit; and clinicians may prescribe a medication that is inappropriate for a patient's financial situation. In addition, caregivers play an important role in patients' care and the education of caregivers can improve adherence to therapies prescribed to the patient. ${ }^{68}$

Personalized approaches to education may be preferred in order to improve adherence to prescribed therapies and uptake of positive lifestyle modifications. Improving patient knowledge about stroke and the benefits of secondary prevention medications is important because attitudes to medications affect their utilization. Patients who believed the benefits of their medication to be low were found to be less likely to be adherent when compared to patients who believed that the benefits of their medications were outweighed by the negatives ${ }^{69}$ Similarly, in a study of patients who had suffered a stroke, those who reported poor adherence to medications more often believed that their medications were not useful. ${ }^{70}$ Ongoing utilization of secondary prevention medications is associated with a better understanding of reasons for taking medications. . $^{71,72}$

Educating patients about the medications and lifestyle changes that reduce the risk of stroke recurrence are likely to improve adherence to recommended therapies. ${ }^{73}$ There is some evidence that providing detailed information about medications improves adherence. ${ }^{74}$ The effect of these educational interventions on clinical outcomes such as recurrent stroke and mortality is unknown. However, such interventions should be considered as better adherence to medications is associated with better outcomes. ${ }^{28,29}$ Education has also been shown to be effective for improving clinical outcomes in patients with heart disease, and so may be similarly effective for patients who have suffered a stroke. ${ }^{75}$ In patients with heart disease, secondary prevention programs with risk factor education and counseling reduced all-cause mortality by $13 \%$, and improved risk factor profiles and utilization of prevention medications. ${ }^{75}$

The method of educating patients is important when encouraging better adherence to recommended lifestyle changes. Advice to change behaviors for stroke prevention is most effective at changing health behaviors when using a motivational interviewing framework. ${ }^{76}$ Motivational interviewing is a counseling method used to encourage behavior 
change by building motivation to change in a way that is directive and patient-centered. ${ }^{76,77}$ The four guiding principles of motivational interviewing are: 1) resisting the righting reflex and exploring motivations for change; 2) understanding patients' motivations; 3) listening with empathy; 4) empowering your patient. ${ }^{77}$ Motivational interviewing is effective for reducing alcohol consumption, weight, serum cholesterol levels, and systolic blood pressure, ${ }^{76}$ increasing smoking cessation, ${ }^{78}$ and improving adherence to antihypertensive medications. ${ }^{79}$ There may be merit in using social media and digital platforms to deliver personalized patient education in future, but this requires further research to determine its effectiveness in encouraging behavior change. ${ }^{80-82}$

\section{Limitations of a personalized approach}

Personalized health care may require considerable time investment from health care providers and patients, particularly the educational interventions for encouraging lifestyle behavior change. Multiple education sessions are recommended in order to have patients consider changes, prepare for change, and maintain change. ${ }^{83}$ In addition, clinicians require training in effective educational techniques such as motivational interviewing.

A personalized approach to health care may be limited depending on the patient's level of autonomy. For example, patients who are cognitively impaired may not be able to express their preferences and values, and therefore would be unable to actively participate in the decision-making process about their treatment. Health care providers would require greater input from the patient's family or carer in these instances.

There may be challenges to providing personalized care for people with concurrent illnesses. There may be difficulties coordinating care when consultations with multiple health care providers are required and conflicting recommendations from different providers may need resolution. Generally, patients with several concurrent illnesses require a greater number of medications. Promoting adherence to therapies can be challenging in these circumstances. Funding policies for chronic disease management that support more streamlined care between multiple clinicians and permit greater time for education are required. In Australia, GPs are reimbursed for providing or coordinating such activities through Medicare, the national public health care scheme.

\section{Conclusion}

Improvements in the prevention of stroke can be achieved with greater personalization of care. Firstly, appropriate selection of patients eligible for therapies is required and should be based on their risk profile. Selection of eligible patients has become more personalized with the development of more complex risk stratification tools. Secondly, in those found to be eligible for therapies used for the prevention of stroke, personalized care should be provided. Patients' preferences and values should be considered in a coordinated model of care. Additionally, provision of emotional and physical support, education and involvement of family and friends is recommended.

Existing treatment protocols recommended in guidelines may change as risk stratification tools are constantly refined. Further work is required to develop effective care planning and education interventions for the prevention of stroke. Tools to facilitate shared decision-making for time-poor clinicians and appropriate funding policies to support these activities are needed, including those that maximize the potential for interdisciplinary care and communication. Overall, personalized medicine in the context of stroke assists delivery of therapy and may improve adherence to prescribed therapies, which in turn should improve outcomes for patients.

\section{Acknowledgments}

The STAND FIRM trial was funded by the NHMRC (586605). Thanks to Sue Mosley and Mary Staios who undertook the education visits for the STAND FIRM trial.

\section{Disclosure}

DAC has an unrestricted educational grant from Boehringer Ingelheim for the Victorian Stroke Telemedicine Project and the Australian Stroke Clinical Registry. AGT was supported by NHMRC grant 1042600. DAC was supported by a research fellowship from the NHMRC (1063761) co-funded by National Heart Foundation. MRN has participated in trials that have received funding from SmithKline Beecham, AstraZeneca, Bayer, Sanofi-Aventis, Merck Sharp and Dohme, Pfizer, Servier Laboratories, and Bristol-Myers Squibb and has served on advisory boards for Sanofi-Aventis, Novartis, Schering-Plough, Solvay Pharmaceuticals, and AMGEN. He has also prepared educational material for Servier Laboratories, AstraZeneca, Bristol-Myers Squibb, and MediMark and received conference and travel support from Bayer HealthCare AG, Merck Sharp and Dohme, Novartis, and Sanofi-Aventis. CFB has an unrestricted educational grant from Boehringer Ingelheim for the Victorian Stroke Telemedicine Project. The authors have no other conflicts of interest to disclose. 


\section{References}

1. O’Donnell MJ, Xavier D, Liu L, et al. Risk factors for ischaemic and intracerebral haemorrhagic stroke in 22 countries (the INTERSTROKE study): a case-control study. Lancet. 2010;376(9735):112-123.

2. Murray CJ, Lopez AD. Measuring the Global Burden of Disease. N Engl J Med. 2013;369(5):448-457.

3. Feigin VL, Forouzanfar MH, Krishnamurthi R, et al. Global and regional burden of stroke during 1990-2010: findings from the Global Burden of Disease Study 2010. Lancet. 2014;383(9913):245-254.

4. Meschia JF, Bushnell C, Boden-Albala B, et al. Guidelines for the primary prevention of stroke: a statement for healthcare professionals from the American Heart Association/American Stroke Association. Stroke. 2014;45(12):3754-3832.

5. Kernan WN, Ovbiagele B, Black HR, et al. Guidelines for the prevention of stroke in patients with stroke and transient ischemic attack: a guideline for healthcare professionals from the American Heart Association/ American Stroke Association. Stroke. 2014;45(7):2160-2236.

6. Heuschmann PU, Kircher J, Nowe T, et al. Control of main risk factors after ischaemic stroke across Europe: data from the stroke-specific module of the EUROASPIRE III survey. Eur J Prev Cardiol. 2015; 22(10):1354-1362.

7. Thrift AG, Srikanth VK, Nelson MR, et al. Risk factor management in survivors of stroke: a double-blind, cluster-randomized, controlled trial. Int J Stroke. 2014;9(5):652-657.

8. Thomas DR. A General Inductive Approach for Analyzing Qualitative Evaluation Data. American Journal of Evaluation. 2006; 27(2):237-246.

9. Australian Government National Health and Medical Research Council [homepage on the Internet]. Guidelines for the management of absolute cardiovascular disease risk. National Vascular Disease Prevention Alliance; 2012. Available from: https://www.nhmrc.gov.au/guidelinespublications/ext10. Accessed October 14, 2015.

10. Feigin VL, Norrving B. A new paradigm for primary prevention strategy in people with elevated risk of stroke. Int J Stroke. 2014; 9(5):624-626.

11. Parmar P, Krishnamurthi R, Ikram MA, et al. The Stroke Riskometer(TM) App: validation of a data collection tool and stroke risk predictor. Int $J$ Stroke. 2015;10(2):231-244.

12. MohanKM, WolfeCD, RuddAG, HeuschmannPU, Kolominsky-Rabas PL, Grieve AP. Risk and cumulative risk of stroke recurrence: a systematic review and meta-analysis. Stroke. 2011; 42(5):1489-1494.

13. Wu CM, McLaughlin K, Lorenzetti DL, Hill MD, Manns BJ, Ghali WA. Early Risk of Stroke After Transient Ischemic Attack: A Systematic Review and Meta-analysis. Arch Intern Med. 2007;167(22):2417-2422.

14. Cadilhac DA, Carter R, Thrift AG, Dewey HM. Organized blood pressure control programs to prevent stroke in Australia: would they be cost-effective? Stroke. 2012;43(5):1370-1375.

15. Lakhan SE, Sapko MT. Blood pressure lowering treatment for preventing stroke recurrence: a systematic review and meta-analysis. Int Arch Med. 2009;2(1):30.

16. Manktelow BN, Potter JF. Interventions in the management of serum lipids for preventing stroke recurrence. Stroke. 2009;8;(3):CD002091.

17. Algra A, van Gijn J. Cumulative meta-analysis of aspirin efficacy after cerebral ischaemia of arterial origin. J Neurol Neurosurg Psychiatry. 1999;66(2):255.

18. Halkes PH, Gray LJ, Bath PM, et al. Dipyridamole plus aspirin versus aspirin alone in secondary prevention after TIA or stroke: a meta-analysis by risk. J Neurol Neurosurg Psychiatry. 2008;79(11):1218-1223.

19. Saxena R, Koudstaal P. Anticoagulants versus antiplatelet therapy for preventing stroke in patients with nonrheumatic atrial fibrillation and a history of stroke or transient ischemic attack. Cochrane Database Syst Rev. 2004;(4):CD000187.

20. Ntaios G, Papavasileiou V, Diener H-C, Makaritsis K, Michel P. Nonvitamin-K-antagonist oral anticoagulants in patients with atrial fibrillation and previous stroke or transient ischemic attack: a systematic review and meta-analysis of randomized controlled trials. Stroke. 2012; 43(12):3298-3304.
21. Hankey GJ. Anticoagulant therapy for patients with ischaemic stroke. Nat Rev Neurol. 2012;8(6):319-328.

22. Kamel H, Johnston SC, Easton JD, Kim AS. Cost-Effectiveness of Dabigatran Compared With Warfarin for Stroke Prevention in Patients With Atrial Fibrillation and Prior Stroke or Transient Ischemic Attack. Stroke. 2012;43(3):881-883.

23. Working Group on the Summit on Combination Therapy for CVD; Yusuf S, Attaran A, et al. Combination pharmacotherapy to prevent cardiovascular disease: present status and challenges. Eur Heart J. 2014;35(6):353-364.

24. Chobanian AV, Bakris GL, Black HR, et al. Seventh report of the Joint National Committee on Prevention, Detection, Evaluation, and Treatment of High Blood Pressure. Hypertension. 2003;42(6): 1206-1252.

25. Kripalani S, Yao X, Haynes RB. Interventions to enhance medication adherence in chronic medical conditions: a systematic review. Arch Intern Med. 2007;167(6):540-550.

26. Haynes RB, Ackloo E, Sahota N, McDonald HP, Yao X. Interventions for enhancing medication adherence. Cochrane Database Syst Rev. 2008;(2):CD000011.

27. Osterberg L, Blaschke T. Adherence to medication. $N$ Engl J Med. 2005;353(5):487-497.

28. Chowdhury R, Khan H, Heydon E, et al. Adherence to cardiovascular therapy: a meta-analysis of prevalence and clinical consequences. Eur Heart J. 2013;34(38):2940-2948.

29. Perreault S, Yu AY, Cote R, Dragomir A, White-Guay B, Dumas S. Adherence to antihypertensive agents after ischemic stroke and risk of cardiovascular outcomes. Neurology. 2012;79(20):2037-2043.

30. Mazzaglia G, Ambrosioni E, Alacqua M, et al. Adherence to antihypertensive medications and cardiovascular morbidity among newly diagnosed hypertensive patients. Circulation. 2009;120(16): 1598-1605.

31. Khan NA, Yun L, Humphries K, Kapral M. Antihypertensive drug use and adherence after stroke: are there sex differences? Stroke. 2010; 41(7):1445-1449.

32. de Koning JS, Klazinga NS, Koudstaal PJ, et al. Quality of care in stroke prevention: results of an audit study among general practitioners. Prev Med. 2004;38(2):129-136.

33. Schleidgen S, Klingler C, Bertram T, Rogowski WH, Marckmann G. What is personalized medicine: sharpening a vague term based on a systematic literature review. BMC Med Ethics. 2013;14:55.

34. Markus HS. Stroke genetics: prospects for personalized medicine. $B M C$ Med. 2012;10:113.

35. Collins FS, Varmus H. A new initiative on precision medicine. $N$ Engl J Med. 2015;372(9):793-795.

36. Australian Commission on Safety and Quality in Health Care (ACSQHC). Patient-Centred Care: Improving Quality and Safety Through Partnerships with Patients and Consumers. Sydney: ACSQHC; 2011. Available from: http://www.safetyandquality.gov.au/wp-content/ uploads/2012/03/PCC_Paper_August.pdf. Accessed October 16, 2015.

37. Wilkinson GR. Drug metabolism and variability among patients in drug response. $N$ Engl J Med. 2005;352(21):2211-2221.

38. Pirmohamed M, Burnside G, Eriksson N, et al. A randomized trial of genotype-guided dosing of warfarin. N Engl J Med. 2013; 369(24):2294-2303.

39. Verhoef TI, Ragia G, de Boer A, et al. A randomized trial of genotypeguided dosing of acenocoumarol and phenprocoumon. $N$ Engl J Med. 2013;369(24):2304-2312.

40. Hoffmann TC, Legare F, Simmons MB, et al. Shared decision making: what do clinicians need to know and why should they bother? Med J Aust. 2014;201(1):35-39.

41. Murphy ME, Fahey T, Smith SM. Computer-based clinical decision support for general practitioners. Fam Pract. 2014;31(5):497-498.

42. Garg AX, Adhikari NK, McDonald H, et al. Effects of computerized clinical decision support systems on practitioner performance and patient outcomes: a systematic review. JAMA. 2005;293(10):1223-1238. 
43. Hill S, Spink J, Cadilhac D, et al. Absolute risk representation in cardiovascular disease prevention: comprehension and preferences of health care consumers and general practitioners involved in a focus group study. BMC Public Health. 2010;10:108.

44. Jansen J, Bonner C, McKinn S, et al. General practitioners' use of absolute risk versus individual risk factors in cardiovascular disease prevention: an experimental study. BMJ Open. 2014;4(5):e004812.

45. Lane DA, Lip GY. Use of the CHA2DS2-VASc and HAS-BLED Scores to aid decision making for thromboprophylaxis in nonvalvular atrial fibrillation. Circulation. 2012;126(7):860-865.

46. Heeley E, Anderson C, Patel A, et al. Disparities between prescribing of secondary prevention therapies for stroke and coronary artery disease in general practice. Int J Stroke. 2012;7(8):649-654.

47. Saposnik G, Goodman SG, Leiter LA, et al. Applying the Evidence: Do Patients With Stroke, Coronary Artery Disease, or Both Achieve Similar Treatment Goals? Stroke. 2009;40(4):1417-1424.

48. Andrew NE, Kilkenny MF, Naylor R, et al. Understanding long-term unmet needs in Australian survivors of stroke. Int J Stroke. 2014;9 Suppl A100:106-112.

49. National Stroke Foundation. Clinical Guidelines for Acute Stroke Management. Melbourne: National Stroke Foundation; 2010. Available from: https://www.nhmrc.gov.au/_files_nhmrc/publications/ attachments/cp126.pdf. Accessed October 16, 2015.

50. Australian Government Department of Health [homepage on the Internet. Chronic Disease Management (formerly Enhanced Primary Care or EPC) - GP services. Australian Government Department of Health; 2014. Available from: http://www.health.gov.au/internet/main/ publishing.nsf/content/mbsprimarycare-chronicdiseasemanagement. Accessed October 14, 2015.

51. Clark AM, Haykowsky M, Kryworuchko J, et al. A meta-analysis of randomized control trials of home-based secondary prevention programs for coronary artery disease. Eur J Cardiovasc Prev Rehabil. 2010; 17(3):261-270.

52. Buckley BS, Byrne MC, Smith SM. Service organisation for the secondary prevention of ischaemic heart disease in primary care. Cochrane Database Syst Rev. 2010(3):CD006772.

53. Lager KE, Mistri AK, Khunti K, Haunton VJ, Sett AK, Wilson AD. Interventions for improving modifiable risk factor control in the secondary prevention of stroke. Cochrane Database Syst Rev. 2014;5: CD009103.

54. Fahey T, Schroeder K, Ebrahim S. Interventions used to improve control of blood pressure in patients with hypertension. Cochrane Database Syst Rev. 2006(2):CD005182.

55. Renders CM, Valk GD, Griffin S, Wagner EH, Eijk JT, Assendelft WJ. Interventions to improve the management of diabetes mellitus in primary care, outpatient and community settings. Cochrane Database Syst Rev. 2001(1):CD001481.

56. Shaffer J, Wexler LF. Reducing low-density lipoprotein cholesterol levels in an ambulatory care system. Results of a multidisciplinary collaborative practice lipid clinic compared with traditional physician-based care. Arch Intern Med. 1995;155(21):2330-2335.

57. Hendriks JM, de Wit R, Crijns HJ, et al. Nurse-led care vs usual care for patients with atrial fibrillation: results of a randomized trial of integrated chronic care vs routine clinical care in ambulatory patients with atrial fibrillation. Eur Heart J. 2012;33(21):2692-2699.

58. Murchie P, Campbell NC, Ritchie LD, Simpson JA, Thain J. Secondary prevention clinics for coronary heart disease: four year follow up of a randomised controlled trial in primary care. BMJ. 2003; 326(7380):84.

59. Munoz MA, Vila J, Cabañero M, et al. Efficacy of an intensive prevention program in coronary patients in primary care, a randomised clinical trial. Int J Cardiol. 2007;118(3):312-320.

60. Khunti K, Stone M, Paul S, et al. Disease management programme for secondary prevention of coronary heart disease and heart failure in primary care: a cluster randomised controlled trial. Heart. 2007; 93(11):1398-1405.
61. Wood DA, Kotseva K, Connolly S, et al. Nurse-coordinated multidisciplinary, family-based cardiovascular disease prevention programme (EUROACTION) for patients with coronary heart disease and asymptomatic individuals at high risk of cardiovascular disease: a paired, cluster-randomised controlled trial. Lancet. 2008; 371(9629):1999-2012.

62. Murphy AW, Cupples ME, Smith SM, et al. Effect of tailored practice and patient care plans on secondary prevention of heart disease in general practice: cluster randomised controlled trial. BMJ. 2009;339:b4220.

63. Ellis G, Rodger J, McAlpine C, Langhorne P. The impact of stroke nurse specialist input on risk factor modification: a randomised controlled trial. Age Ageing. 2005;34(4):389-392.

64. Joubert J, Reid C, Barton D, et al. Integrated care improves risk-factor modification after stroke: initial results of the Integrated Care for the Reduction of Secondary Stroke model. J Neurol Neurosurg Psychiatry. 2009;80(3):279-284.

65. Allen K, Hazelett S, Jarjoura D, et al. A randomized trial testing the superiority of a postdischarge care management model for stroke survivors. J Stroke Cerebrovasc Dis. 2009;18(6):443-452.

66. Wolfe CDA, Redfern J, RuddAG, GrieveAP, Heuschmann PU, McKevittC. Cluster randomized controlled trial of a patient and general practitioner intervention to improve the management of multiple risk factors after stroke. Stroke. 2010;41(11):2470-2476.

67. Flemming KD, Allison TG, Covalt JL, Herzig DE, Brown RD. Utility of a post-hospitalization stroke prevention program managed by nurses. Hosp Pract (1995). 2013;41(3):70-79.

68. Ferguson C, Inglis SC, Newton PJ, Middleton S, Macdonald PS, Davidson PM. The caregiver role in thromboprophylaxis management in atrial fibrillation: A literature review. Eur J Cardiovasc Nurs. 2015; 14(2):98-107.

69. Chambers JA, O'Carroll RE, Hamilton B, et al. Adherence to medication in stroke survivors: a qualitative comparison of low and high adherers. Br J Health Psychol. 2011;16(3):592-609.

70. Sjölander M, Eriksson M, Glader EL. The association between patients' beliefs about medicines and adherence to drug treatment after stroke: a cross-sectional questionnaire survey. BMJ Open. 2013; 3(9):e003551.

71. Bushnell CD, Zimmer LO, Pan W, et al. Persistence With Stroke Prevention Medications 3 Months After Hospitalization. Arch Neurol. 2010;67(12):1456-1463.

72. Bushnell CD, Olson DM, Zhao X, et al. Secondary preventive medication persistence and adherence 1 year after stroke. Neurology. 2011;77(12):1182-1190.

73. Maasland L, Brouwer-Goossensen D, den Hertog HM, Koudstaal PJ, Dippel DW. Health education in patients with a recent stroke or transient ischaemic attack: a comprehensive review. Int J Stroke. 2011; 6(1):67-74.

74. Hohmann C, Neumann-Haefelin T, Klotz JM, Freidank A, Radziwill R. Adherence to hospital discharge medication in patients with ischemic stroke: a prospective, interventional 2-phase study. Stroke. 2013; 44(2):522-524.

75. Clark AM, Hartling L, Vandermeer B, McAlister FA. Meta-analysis: secondary prevention programs for patients with coronary artery disease. Ann Intern Med. 2005;143(9):659-672.

76. Rubak S, Sandbæk A, Lauritzen T, Christensen B. Motivational interviewing: a systematic review and meta-analysis. Br J Gen Pract. 2005;55(513):305-312.

77. Hall K, Gibbie T, Lubman DI. Motivational interviewing techniques facilitating behaviour change in the general practice setting. Aust Fam Physician. 2012;41(9):660-667.

78. Lai DT, Cahill K, Qin Y, Tang JL. Motivational interviewing for smoking cessation. Cochrane Database Syst Rev. 2010(1):CD006936.

79. Schroeder K, Fahey T, Ebrahim S. Interventions for improving adherence to treatment in patients with high blood pressure in ambulatory settings. Cochrane Database Syst Rev. 2004(2): CD004804 
80. Moorhead SA, Hazlett DE, Harrison L, Carroll JK, Irwin A, Hoving C. A new dimension of health care: systematic review of the uses, benefits, and limitations of social media for health communication. J Med Internet Res. 2013;15(4):e85.

81. Marquez Contreras E, de la Figuera von Wichmann M, Gil Guillen V, et al. Effectiveness of an intervention to provide information to patients with hypertension as short text messages and reminders sent to their mobile phone (HTA-Alert). Aten Primaria. 2004;34(8):399-405.
82. Redfern J, Thiagalingam A, Jan S, et al. Development of a set of mobile phone text messages designed for prevention of recurrent cardiovascular events. Eur J Prev Cardiol. 2014;21(4):492-499.

83. Koenigsberg MR, Bartlett D, Cramer JS. Facilitating treatment adherence with lifestyle changes in diabetes. Am Fam Physician. 2004;69(2):309-316.

\section{Publish your work in this journal}

Vascular Health and Risk Management is an international, peerreviewed journal of therapeutics and risk management, focusing on concise rapid reporting of clinical studies on the processes involved in the maintenance of vascular health; the monitoring, prevention and treatment of vascular disease and its sequelae; and the involvement of metabolic disorders, particularly diabetes. This journal is indexed on PubMed Central and MedLine. The manuscript management system is completely online and includes a very quick and fair peer-review system, which is all easy to use. Visit http://www.dovepress.com/ testimonials.php to read real quotes from published authors.

Submit your manuscript here: http://www.dovepress.com/vascular-health-and-risk-management-journal 